\title{
Condicionamento fisiológico de sementes de soja, componentes de produção e produtividade
}

\author{
Seed priming, yield components and yield of soybean
}

\author{
Tiago Alexandre da Silva ${ }^{I^{*}}$ Pedro Bento da Silva ${ }^{\mathrm{I}}$ Edvaldo Aparecido Amaral da Silva ${ }^{\mathrm{I}}$ \\ João Nakagawa' Claudio Cavariani ${ }^{\mathrm{I}}$
}

\section{RESUMO}

\begin{abstract}
A cultura da soja apresenta importância comercial extremamente relevante para a economia brasileira. $O$ condicionamento fisiológico é uma técnica que permite melhorar a qualidade das sementes, sobretudo daquelas de baixo vigor. $O$ vigor é definido como a capacidade das sementes em apresentar desempenho adequado, quando expostas a diferentes condições ambientais. Sementes de alto vigor produzem plantas com maior velocidade de emergência e maiores níveis nos componentes de rendimento, desdobrando assim em uma maior produtividade de sementes no final do seu ciclo. O objetivo foi avaliar o comportamento agronômico em plantas, em condições de campo, oriundas de sementes de soja condicionadas sob diferentes potenciais osmóticos, em função dos níveis de vigor. Foram avaliados os componentes de produção e a produtividade da soja. O condicionamento fisiológico em sementes de médio vigor influencia positivamente nos componentes (emergência de plântulas, altura de inserção da primeira vagem, número de vagens/planta, número de sementes/planta, número de sementes/ vagem) e na produtividade da cultivar 'M7211RR' de soja. Os diferentes níveis de vigor das sementes de soja ocasionam diferenças no número de vagens/planta.
\end{abstract}

Palavras-chave: condicionamento osmótico, deterioração, vigor de sementes.

\section{ABSTRACT}

The Soybean crop is extremely relevant to the Brazilian economy. Priming is a technique that allows improvement of seed quality, especially those of low vigor. Vigor is defined as the ability of the seed to perform adequately when exposed to different environmental conditions. High vigor seeds generate plants with higher emergency speed and superior yield components, favoring into a higher seed yield. The objective of this work was to evaluate the agronomic behavior of soybean plants under field conditions originated from primed seeds with different level of vigor. Yield components and soybean yield were also evaluated. Seed priming in seed with medium vigor positively influences the components (seedling emergence, first pod height, number pods/plant, number of seeds/plant, number of seeds/ pod) and favored productivity of soybean cultivar 'M7211RR'. Different levels of vigor of soybean seeds cause differences in the number of pods/plant.

Key words: priming, deterioration, seed vigor.

\section{INTRODUÇÃO}

A produtividade da cultura da soja (Glycine max (L.) Merrill) no Brasil é crescente, devido à utilização de tecnologia adequada por parte dos produtores. Destaca-se também o fomento da pesquisa e a obtenção de novas cultivares mais produtivas e menos susceptíveis às condições adversas que acometem a cultura.

A qualidade fisiológica das sementes pode ser caracterizada pelo vigor e pela germinação. $O$ vigor das sementes é a soma de atributos que confere à semente o potencial para germinar, emergir e resultar rapidamente em plântulas normais sob ampla diversidade de condições ambientais (HÖFS et al., 2004).

$\mathrm{O}$ vigor das sementes é inversamente proporcional ao processo de deterioração. A deterioração reduz a qualidade, viabilidade e vigor das sementes, devido ao envelhecimento ou efeito de fatores ambientais adversos (SIADAT et al., 2012). A deterioração é um processo determinado por uma

'Departamento de Produção e Melhoramento Vegetal, Universidade Estadual Paulista (UNESP), Botucatu, SP, Brasil. E-mail: tiago.at.agro@hotmail.com. Autor para correspondência. 
série de alterações fisiológicas, bioquímicas, físicas e citológicas, com início a partir da maturidade fisiológica, em ritmo progressivo, determinando a queda da qualidade e culminando com a morte da semente (MARCOS FILHO, 2005).

O condicionamento fisiológico é uma técnica na qual sementes em estádio avançado de deterioração têm incremento na qualidade fisiológica, com efeito no vigor, permitindo um melhor aproveitamento dessas sementes (LANTERI et al., 1996). Diversos trabalhos têm demonstrado que o vigor das sementes é o componente da qualidade fisiológica mais influenciado pelo condicionamento fisiológico, que tem sido utilizado para reduzir os danos do envelhecimento e favorecer o seu desempenho em sementes de muitas culturas (SILVA et al., 2006; FAROOQ et al., 2009). Por essa razão, o tratamento tem sido comumente designado na literatura como um revigoramento de sementes.

O condicionamento osmótico em sementes de soja resulta em melhoras significativas na germinação e no vigor das sementes (ARIF et al., 2008). Existem poucos trabalhos em sementes de soja, na literatura, relacionados aos efeitos do condicionamento osmótico nos componentes de produção e na produtividade. Porém, NUNES et. al. (2002) verificaram que a produtividade da cultura da soja apresenta resultados superiores, na qual as sementes são submetidas ao condicionamento osmótico. Segundo MOHAMMIDI (2009), o condicionamento osmótico proporciona aumento na produtividade de soja.

A técnica do condicionamento fisiológico em sementes de soja, embora ainda não seja utilizado comercialmente, pode ter a sua aplicação em pequenos volumes de sementes, armazenados em bancos de sementes ou em coleções pertencentes a melhoristas, quando em processo de deterioração. Nesses casos, o condicionamento fisiológico pode ser útil na melhoria da qualidade fisiológica das sementes.

Dentro desse contexto, o objetivo foi avaliar o comportamento agronômico de plantas oriundas de sementes de soja condicionadas em diferentes potenciais osmóticos, em função dos níveis de vigor.

\section{MATERIAL E MÉTODOS}

O trabalho foi instalado e conduzido durante o ano agrícola de 2012/2013 no Laboratório de Análise de Sementes do Departamento de Produção e Melhoramento Vegetal (DPMV) e na área da Fazenda Experimental Lageado, pertencentes a UNESP/FCA, Campus de Botucatu-SP. Foram utilizadas sementes de soja da cultivar 'M7211RR'.
Os diferentes níveis de vigor foram obtidos envelhecendo as sementes em caixas plásticas transparentes $(11 \times 11 \times 3,5 \mathrm{~cm})$, com UR de $90 \%$ a $41^{\circ} \mathrm{C}$, durante 36 e $48 \mathrm{~h}$ (médio e baixo vigor, respectivamente). Após o envelhecimento, as sementes foram condicionadas em PEG 6000 a $-1,0$ e $-1,2 \mathrm{MPa}$ a $25^{\circ} \mathrm{C}$, por um período de $12 \mathrm{~h}$, segundo SADEGHI (2011). Em seguida, as sementes foram lavadas em água corrente e colocadas em bandejas contendo papel toalha por duas horas e levadas em saco plástico para o campo, onde foram semeadas.

Os dados climáticos foram coletados diariamente, com temperatura de $24,7^{\circ} \mathrm{C}$ durante o ciclo e com precipitação pluvial de $85 \mathrm{~mm}$ no período de emergência de plântulas (15 dias), 433mm no período vegetativo ( 34 dias) e de $812 \mathrm{~mm}$ no período reprodutivo (85 dias), sendo chuvas concentradas e mal distribuídas nesses períodos; foi realizada a calagem e a adubação de semeadura (RAIJ et al., 1997). A instalação do experimento ocorreu em 22 de novembro de 2012, em área anteriormente cultivada com aveia preta (Avena strigosa) no período da entressafra. O desbaste foi realizado 25 dias após a emergência de todas as plântulas, considerando a densidade populacional desejada de $13 \mathrm{pl} \mathrm{m}^{-1}$, de modo a proporcionar equidistância entre as plantas na linha.

Foram realizadas avaliações de emergência de plântulas, índice de velocidade de emergência (IVE), altura de plantas, altura de inserção da primeira vagem, número de vagens/planta, número de sementes/planta, número de sementes/vagem e produtividade.

O experimento foi disposto em blocos ao acaso, em esquema fatorial, $2 \times 3+1$, correspondendo a dois níveis de vigor (médio e baixo), três potenciais osmóticos (Testemunha (sementes não condicionadas), -1,0 e -1,2MPa) e uma testemunha adicional de sementes secas de alto vigor sem condicionamento, com três repetições. Cada unidade experimental foi constituída por cinco fileiras de $3 \mathrm{~m}$ de comprimento. Para as avaliações, foram consideradas as três linhas centrais, desprezando-se $0,50 \mathrm{~m}$ de cada uma de suas extremidades e uma fileira de cada lado da unidade experimental. As médias foram comparadas pelo teste de Tukey $(\mathrm{P} \leq 0,05)$ e a testemunha adicional foi comparada com os demais tratamentos pelo teste de Dunnett.

\section{RESULTADOS E DISCUSSÃO}

A porcentagem de emergência de plântulas foi superior quando sementes de médio vigor foram condicionadas a $-1,0 \mathrm{MPa}$, diferenciando das 
sementes condicionadas a $-1,2 \mathrm{MPa}$, sem diferir, porém, da testemunha (Tabela 1). O condicionamento osmótico das sementes de baixo vigor não produziu benefícios à emergência de plântulas. Lotes com desempenho muito deficiente seriam constituídos por proporção elevada de sementes em estádio avançado de deterioração, que demandariam consumo significativo de energia para probabilidade de sucesso do condicionamento (MARCOS FILHO, 2005).

$\mathrm{O}$ condicionamento fisiológico em sementes de médio vigor não beneficiou a velocidade de emergência. Nas sementes de baixo vigor, as sementes condicionadas a $-1,0 \mathrm{MPa}$ apresentaram um maior índice de velocidade de emergência, porém não diferindo dos demais tratamentos dentro do nível de vigor (Tabela 1). Segundo COPELAND \& MCDONALD (1985), descrevendo uma série de sintomas relacionados a alterações no desempenho das sementes devido à progressão na deterioração, comentaram que um dos primeiros eventos a ocorrer é retardamento na emergência, seguido de decréscimos na emergência e crescimento mais lento de plântulas, caso não observado nesses resultados.

Em sementes de baixo vigor, o desempenho do IVE foi superior para o tratamento condicionado a -1,0MPa, diferindo significativamente das sementes condicionadas a -1,2MPa. Alguns trabalhos também mostraram os benefícios do condicionamento fisiológico na melhoria da emergência de plântulas, e os benefícios subsequentes, como rendimento e precocidade. (SHAH et al., 2012).

Não houve diferença na altura de plantas para as sementes de médio vigor. Considerando altura de plantas, valores numéricos superiores foram constatados quando estas foram oriundas de sementes de baixo vigor, submetidas ao condicionamento osmótico de -1,0 e 1,2MPa, porém sem diferir significativamente daquelas que não

Tabela 1 - Efeito do condicionamento fisiológico na emergência de plântulas, índice de velocidade de emergência, altura de planta e na altura de inserção da primeira vagem da planta de soja.

\begin{tabular}{|c|c|c|c|c|}
\hline Tratamentos & Testemunha & $-1,0 \mathrm{Mpa}$ & $-1,2 \mathrm{Mpa}$ & Médias \\
\hline Médio Vigor & $54,07 \mathrm{Aab}^{*}$ & $60,34 \mathrm{Aa}$ & $47,56 \mathrm{Ab}^{*}$ & 54,00 \\
\hline Baixo Vigor & $59,14 \mathrm{Aa}$ & $47,89 \mathrm{Bb}^{*}$ & $48,22 \mathrm{Ab}^{*}$ & 51,75 \\
\hline Média Geral & 56,60 & 54,12 & 47,89 & \\
\hline Adicional & 75,15 & & & \\
\hline C.V. & 7,44 & & & \\
\hline Tratamentos & Testemunha & $\begin{array}{l}\text { nergência--- } \\
-1,0 \mathrm{MPa}\end{array}$ & $-1,2 \mathrm{Mpa}$ & Médias \\
\hline Médio Vigor & 10,42 & 9,71 & $8,63^{*}$ & $9,59 \mathrm{~A}$ \\
\hline Baixo Vigor & 9,91 & 11,53 & 8,66 & $10,04 \mathrm{~A}$ \\
\hline Média Geral & $10,16 \mathrm{a}$ & $10,62 \mathrm{a}$ & $8,65 \mathrm{~b}$ & \\
\hline Adicional & 10,56 & & & \\
\hline C.V. & 6,93 & & & \\
\hline Tratamentos & Testemunha & $-1,0 \mathrm{MPa}$ & $-1,2 \mathrm{Mpa}$ & Médias \\
\hline Médio Vigor & 97,91 & 96,97 & 95,45 & $96,77 \mathrm{~A}$ \\
\hline Baixo Vigor & 86,99 & 92,83 & 96,21 & $92,01 \mathrm{~A}$ \\
\hline Média Geral & $92,45 \mathrm{a}$ & $94,83 \mathrm{a}$ & $95,83 \mathrm{a}$ & \\
\hline Adicional & 95,23 & & & \\
\hline C.V. & 5,26 & & & \\
\hline Tratamentos & --------Altura & a vagem $(\mathrm{cm}$ & & \\
\hline Tratamentos & Testemunha & -1,0 Mpa & -1,2 Мра & Médias \\
\hline Médio Vigor & $13,25 \mathrm{Ab}$ & $11,86 \mathrm{Bb}$ & $\begin{array}{l}16,57 \mathrm{Aa}^{*} \\
13,40 \mathrm{Ba}\end{array}$ & $\begin{array}{l}13,89 \\
140 ?\end{array}$ \\
\hline Baixo Vigor & 14,08 Aa & $14,58 \mathrm{Aa}$ & $13,40 \mathrm{Ba}$ & 14,02 \\
\hline Média Geral & 13,66 & 13,22 & 14,98 & \\
\hline Adicional & 11,20 & & & \\
\hline C.V. & 9,55 & & & \\
\hline
\end{tabular}

${ }^{1}$ médias seguidas pela mesma letra, minúscula na linha e maiúscula na coluna, não diferem entre si pelo teste Tukey P $\left.\leq 0,05\right)$. ${ }^{*}$ Difere da média do tratamento adicional pelo teste Dunnett. 
receberam tratamento pré-semeadura. A testemunha adicional não se diferenciou dos tratamentos para esta variável (Tabela 1).

Para a altura da inserção da primeira vagem, as sementes de médio vigor condicionadas a $-1,2 \mathrm{MPa}$ apresentaram altura superior, diferindo das não condicionadas e da condicionada a -1,0MPa. Não houve diferença na altura de inserção da primeira vagem em sementes de baixo vigor. Todos os tratamentos apresentaram maior altura de inserção da primeira vagem comparada com a testemunha adicional, porém só o tratamento constituído por sementes de médio vigor, submetidas ao condicionamento de -1,2Mpa, apresentou diferença significativa (Tabela 1 ).

SPEROTTO et al. (1999), avaliando os efeitos do condicionamento osmótico e da aplicação de zinco sobre o desempenho de sementes e plantas de feijoeiro (Phaseolus vulgaris L.), observou que o condicionamento osmótico não alterou significativamente a altura da inserção da primeira vagem, discordando dos resultados obtidos. A inserção da primeira vagem é uma característica importante, pois determina a regulagem da altura da barra de corte da colhedora, visando a obter a máxima eficiência durante esse processo.

As sementes condicionadas em potencial osmótico de -1,0 e -1,2MPa, tanto para as sementes de médio e baixo vigor, apresentaram diferença significativa em número de vagens/planta, comparadas com as sementes que não sofreram tratamento pré-semeadura. Para essa mesma variável, todos os tratamentos que receberam condicionamento em sementes de baixo vigor demonstraram resultados com diferença estatística comparados com a testemunha adicional (Tabela 2).

MOHAMMADI (2009), avaliando os efeitos do condicionamento osmótico com sais em sementes de soja no desempenho de plantas, verificou o aumento dos componentes de produção, enfatizando o número de vagens por planta, diferindo estatisticamente da testemunha.

Sementes de baixo e médio vigor apresentaram plantas com maior número de sementes, quando condicionadas a -1,0 e -1,2MPa (Tabela 2). As sementes de médio vigor condicionadas a $-1,0$ e $-1,2 \mathrm{MPa}$ obtiveram um desempenho superior, de aproximadamente $40,6 \%$ e $38,97 \%$, respectivamente, em comparação à testemunha do mesmo vigor. De forma semelhante, as sementes de baixo vigor condicionadas a $-1,0$ e $-1,2 \mathrm{MPa}$, apresentaram um incremento médio de $40,90 \%$ e $41,96 \%$, respectivamente, comparado com sua testemunha.
O condicionamento osmótico aumentou o número médio de sementes por vagem em sementes de médio e baixo vigor, havendo diferença significativa nas sementes de médio vigor condicionadas a $-1,2$ com os demais tratamentos. Em comparação com a testemunha adicional, as sementes de médio vigor condicionadas a $-1,2 \mathrm{MPa}$ apresentaram diferença significativa (Tabela 2).

Avaliando os efeitos do condicionamento osmótico com sais nas características de plantas de soja no final da primavera, MOHAMMADI (2009) concluiu que os tratamentos com nitrato de potássio, nitrato de amônia e nitrato de cálcio aumentaram significativamente os componentes de produção, destacando o número de sementes por planta e o número médio de sementes por vagem.

Em relação à variável produtividade, o condicionamento osmótico favoreceu as sementes de médio vigor (Tabela 2). Fato diferente foi observado nas sementes de baixo vigor, onde houve uma diminuição da produtividade de 0,28 e 1,13\% naquelas que foram condicionadas a $-1,0$ e -1,2Mpa, respectivamente, comparadas com as sementes que não receberam tratamento pré-semeadura.

Para as sementes de médio vigor, o condicionamento favoreceu a produtividade, principalmente nas que foram condicionadas a -1,0MPa, porém não apresentou diferença significativa dentro desse nível de vigor se comparada à testemunha adicional. O condicionamento osmótico favoreceu um ganho de $7,72 \%$ para sementes condicionadas a $-1,0 \mathrm{MPa}$ e de $1,62 \%$ para as sementes condicionadas a $-1,2 \mathrm{MPa}$, em relação às sementes que não foram submetidas ao condicionamento.

Resultados semelhantes foram encontrados por NUNES et. al. (2002), em que o condicionamento osmótico proporcionou resultados superiores para produtividade, quando comparado ao tratamento sem condicionamento, e com a utilização de sementes colhidas no estádio R8. Esses resultados corroboram os obtidos por MOHAMMADI (2009), o qual verificou que a produtividade de soja foi significativamente superior com o condicionamento osmótico de sementes.

Os resultados do presente trabalho podem ser justificados pela ação do condicionamento fisiológico, que favorece tolerância em sementes em condições adversas, provocadas, neste caso, por ocorrência de períodos de ausência de precipitação pluvial na fase inicial do ciclo (ocorrendo o atraso da floração) e também no período de enchimento de vagem.

A tolerância a estresse trata-se de uma das principais vantagens do condicionamento, 
Tabela 2 - Efeito do condicionamento fisiológico no número de vagens por planta, número de sementes por planta, número de sementes por vagem e na produtividade de soja.

\begin{tabular}{|c|c|c|c|c|}
\hline Tratamentos & Testemunha & $-1,0 \mathrm{Mpa}$ & $-1,2 \mathrm{MPa}$ & Médias \\
\hline Médio Vigor & 49,86 & 81,15 & 84,60 & $64,41 \mathrm{~A}$ \\
\hline Baixo Vigor & 60,08 & $89,55^{*}$ & $89,90^{*}$ & $68,00 \mathrm{~B}$ \\
\hline Média Geral & $54,97 \mathrm{~b}$ & $85,35 \mathrm{a}$ & $87,25 \mathrm{a}$ & \\
\hline Adicional & 50,00 & & & \\
\hline C.V. & 9,30 & & & \\
\hline Tratamentos & Testemunha & $-1,0 \mathrm{MPa}$ & $-1,2 \mathrm{MPa}$ & Médias \\
\hline Médio Vigor & 92,70 & 156,15 & 151,90 & $133,5 \mathrm{~A}$ \\
\hline Baixo Vigor & 102,81 & $174,05^{*}$ & $177,15^{*}$ & $151,3 \mathrm{~A}$ \\
\hline Média Geral & $97,75 \mathrm{~b}$ & $165,102 \mathrm{a}$ & $164,52 \mathrm{a}$ & \\
\hline Adicional & 88,07 & & & \\
\hline C.V. & 12,55 & & & \\
\hline Tratamentos & Testemunha & $-1,0 \mathrm{MPa}$ & $-1,2 \mathrm{MPa}$ & Médias \\
\hline Médio Vigor & 1,86 & 1,87 & $2,40^{*}$ & $2,04 \mathrm{~A}$ \\
\hline Baixo Vigor & 1,72 & 1,93 & 1,93 & $1,86 \mathrm{~A}$ \\
\hline Média Geral & $1,79 \mathrm{~b}$ & $1,90 \mathrm{ab}$ & $2,16 \mathrm{a}$ & \\
\hline Adicional & 1,80 & & & \\
\hline C.V. & 11,71 & & & \\
\hline & - & de $\left(\mathrm{kg} \mathrm{ha}^{-1}\right)$ & & \\
\hline Tratamentos & Testemunha & $-1,0 \mathrm{MPa}$ & $-1,2 \mathrm{MPa}$ & Médias \\
\hline Médio Vigor & 4112,8 & 4457,1 & 4180,8 & $4250,6 \mathrm{~A}$ \\
\hline Baixo Vigor & 4034,2 & 4034,0 & 3989,1 & $4015,3 \mathrm{~A}$ \\
\hline Média Geral & $4073,5 \mathrm{a}$ & $4239,8 \mathrm{a}$ & $4085,0 \mathrm{a}$ & \\
\hline Adicional & 3988,3 & & & \\
\hline C.V. & 10,56 & & & \\
\hline
\end{tabular}

${ }^{1}$ Médias seguidas pela mesma letra, minúscula na linha e maiúscula na coluna, não diferem entre si pelo teste Tukey (P $\left.\leq 0,05\right)$. ${ }^{*}$ Difere da média do tratamento adicional pelo teste Dunnett.

conferindo assim resistência à queda acentuada ou à elevação de temperatura, à deficiência hídrica e ao aumento da concentração salina, evidenciados frequentemente na literatura.

Segundo BRUCE et al. (2007), um estresse inicial provocado pelo condicionamento fisiológico favorece uma resposta de tolerância para um futuro estresse que a planta possa sofrer. As plantas são capazes de expressar um tipo de "memória", também chamada de "impressão do estresse". Essa impressão, comumente traduzida por modificações genéticas e bioquímicas induzidas por uma primeira exposição ao estresse, aumenta a resistência a uma condição adversa subsequente.

\section{CONCLUSÃO}

O condicionamento fisiológico em sementes de médio vigor influencia positivamente nos componentes (emergência de plântulas, altura de inserção da primeira vagem, número de vagens/planta, número de sementes/planta, número de sementes/ vagem) e na produtividade da cultivar 'M7211RR' de soja. Os diferentes níveis de vigor das sementes de soja ocasionam diferenças no número de vagens/planta.

\section{AGRADECIMENTOS}

O autor agradece a Coordenação de Aperfeiçoamento de Pessoal de Nível Superior (CAPES) pela bolsa Mestrado.

\section{REFERENCIAS}

ARIF, M. et al. Seed priming improves emergence and yield of soybean. Pakistan Journal of Botany, v.40, n.3, p.11691177, 2008. Disponível em: <http://www.researchgate.net/ publication/234077823_Protein_breakdown_represents_a_ major_bottleneck_in_nitrogen_cycling_in_grassland_soils/ file/9fcfd50d2c4ea68c 25 .pdf $>$. Acesso em: 21 jun. 2014. 
BRUCE, T.J.A. et al. Stressful "memories" of plants: evidence and possible mechanisms. Plant Science, v.173, p.603-608, 2007. Disponível em: <http://www.sciencedirect.com/science/article/pii/ S0168945207002476>. Acesso em: 02 maio 2014. doi: 10.1016/j. plantsci.2007.09.002.

COPELAND, L.O.; McDONALD, M.B. Principles of seed science and technology. 3.ed. New York: Chapman \& Hall, 1995. $467 \mathrm{p}$

FAROOQ, M. et al. Improving of drought tolerance in rice (Oryza sativa L.) by exogenous application of salicylic acid. Journal of Agronomy and Crop Science, v.195, p.237246, 2009. Disponível em: <http://www.researchgate.net/ publication/229662322_Improving the_Drought_Tolerance in_Rice_(Oryza_sativa_L.)_by_Exogenous_Application_of Salicylic_Acid/file/72e7e5282600c369f0.pdf>. Acesso em: $2 \overline{3}$ jun. 2014. doi: 10.1111/j.1439-037X.2009.00365.x.

HÖFS, A. et al. Emergência e crescimento de plântulas de arroz em resposta à qualidade fisiológica de sementes. Revista Brasileira de Sementes, v.26, n.1, p.92-97, 2004a. Disponível em: <http:// www.scielo.br/scielo.php?script $=$ sci_arttext\&pid $=$ S0101312220 $04000100014 \& \operatorname{lng}=\mathrm{pt} \&$ nrm $=\mathrm{iso} \& \mathrm{t} \operatorname{lng}=\mathrm{pt}>$. Acesso em: 23 jun. 2014. doi: 10.1590/S0101-31222004000100014.

LANTERI, S. et al. Effects of controlled deterioration and osmoconditioning on germination and nuclear replication in seeds of pepper (Capsicum annuum L.). Annals of Botany, v.77, n.66, p.591-597, 1996. Disponível em: <http://aob.oxfordjournals.org/ content/77/6/591.full.pdf + html $>$. Acesso em: 20 jun. 2014. doi: 10.1093/aob/77.6.591.

MARCOS FILHO, J.M. Fisiologia de sementes de plantas cultivadas. Piracicaba: FEALQ, 2005. 495 p.

MOHAMMADI, G.R. The effect of seed primming on plant traits of late-spring seeded soybean (Glycine max L.). Journal of Agriculture and Environmental Science, v.5, n.3, p.322326, 2009. Disponível em: <http://www.idosi.org/aejaes/ jaes5(3)/4.pdf>. Acesso em: 14 abr. 2015. doi: 10.5829/idosi. aejaes.2012.12.06.1755.
NUNES, U.R. et al. Efeito do condicionamento osmótico de sementes de soja sobre a habilidade competitiva da cultura com as plantas daninhas. Planta Daninha, v.20, n.1, p.27-35, 2002. Disponível em: <http://www.scielo.br/pdf/pd/v21n1/a04v21n1>. Acesso em: 12 abr. 2014.

RAIJ, B. van et al. Recomendações de adubação e calagem para o Estado de São Paulo. Boletim Técnico do Instituto Agronômico de Campinas, n.100, p.285, 1997.

SADEGHI, H. et al. Effect of seed osmopriming on seed germination behavior and vigor of soybean (Glycine max L.). Journal of Agricultural and Biological Science, v.6, n.1, p.39-46, 2011. Disponível em: <http://www.arpnjournals.com/ jabs/research_papers/rp_2011/jabs_0111_231.pdf >. Acesso em: 07 maio 2014.

SHAH, H. et al. Seed priming improves early seedling growth and nutrient uptake in mungbean. Journal Plant Nutrition, v.35, p.805-816, 2012. Disponível em: <http://www.tandfonline. com/doi/abs/10.1080/01904167.2012.663436\#.VGD3avnF-H4>. Acesso em: 22 ago. 2014. doi: 10.1080/01904167.2012.663436.

SIADAT, S.A. et al. Effect of seed priming on antioxidant activity and germination characteristics of Maize seeds under different aging treatments. Research Journals of Seed Science, v.5, n.2, p.51-62, 2012. Disponível em: <http://www.scialert.net/ abstract/?doi=rjss.2012.51.62>. Acesso em: 05 jul. 2014. doi: $10.3923 /$ rjss.2012.51.62.

SILVA, J.B. da; et al. Desempenho de sementes de soja submetidas a diferentes potenciais osmóticos em polietilenoglicol. Ciência Rural, v.36, n.5, p.1634-1637, 2006. Disponível em: <http:// base.repositorio.unesp.br/bitstream/handle/11449/3310/S010384782006000500047.pdf? sequence $=1 \&$ is Allowed $=y>$. Acesso em 14 abr. 2015.

SPEROTTO, C.C.I. et al. Desempenho de sementes e plantas de feijoeiro sob efeito do condicionamento osmótico e da aplicação de zinco. Ciência Rural, v.29, n.2, p.253-257, 1999. Disponível em: <http://www.scielo.br/pdf/cr/v29n2/a11v29n2.pdf >. Acesso em: 03 jul. 2014 